Dicle Üniversitesi Veteriner Fakültesi Dergisi
https://dergipark.org.tr/tr/pub/duvetfd
Araştırma Makalesi/Research Article
Dicle Üniv Vet Fak Derg 2021;14(1):1-6
DOI: 10.47027/duvetfd.725341 $\quad$ e-ISSN:1308-0679

\title{
Solunum Sistemi Hastalıklı Buzağılarda Farklı Oksijen Uygulama Yöntemlerinin Arteriyel ve Venöz Kan Gazları Üzerine Etkileri
}

\author{
Sakine DALĞA ${ }^{1, a}$, Cumali ÖZKAN ${ }^{1, b, 凹}$ \\ ${ }^{1}$ Van Yüzüncü Yıl Üniversitesi, Veteriner Fakültesi, İç Hastalıkları Anabilim Dalı, Van, TÜRKiYE \\ aORCID: 0000-0002-2034-3911; bORCID: 0000-0001-8502-6987
}

\begin{tabular}{ccc}
\hline Geliş Tarihi/Received & Kabul Tarihi/Accepted & Yayın Tarihi/Published \\
22.04 .2020 & 14.01 .2021 & 30.06 .2021 \\
\hline
\end{tabular}

\section{Öz}

Bu çalışmada, solunum sistemi hastalı̆̆ı bulunan ve yapılan kan gazları analizlerine göre oksijen tedavisine ihtiyacı olan buzağılarda, rutin solunum sistemi tedavisine ilave olarak maske ve intranazal kateter ile oksijen uygulamalarının, arteriyel ve venöz kan gazları üzerine etkilerinin belirlenmesi amaçlandı. Çalışmanın materyalini 18 buzağı oluşturdu. Klinik muayene sonucu solunum sistemi problemi olan ve kan gazları sonuçlarına göre oksijen tedavisine ihtiyaç duyan buzağılar çalışmaya dâhil edildi. Buzağılar 1. grup (kontrol), 2. grup (maske) ve 3. grup (intranazal kateter) olmak üzere 3 gruba ayrıldı. 1. grup hayvanlara rutin solunum sistemi hastalığı tedavisi, 2 . grup hayvanlara rutin tedavinin yanı sıra maske ile oksijen tedavisi, 3. grup hayvanlara ise rutin tedaviye ilave olarak intranazal kateter ile oksijen verildi. Kan gazları ölçümleri için 0., 3., 5. ve 24. saatlerinde arteriyel ve venöz kan örnekleri alındı. Solunum güçlüğü bulunan buzağılarda, venöz ve arteriyel kan gazı parametrelerinde grup içi karşılaştırmalarda istatistiksel bazı farklılıklar gözlendi. 1 grup hayvanlarda bu parametrelerde pek bir değişim görülmezken, oksijen tedavisi yapılan 2. ve 3. grup hayvanlarda, özellikle $\mathrm{pCO}_{2}$ seviyelerinin zamanla normale döndüğü, laktat değerlerinin azaldığı ve $\mathrm{SO}_{2}$ ile $\mathrm{pO}_{2}$ değerlerinin ise artış gösterdiği belirlendi. Oksijen uygulaması yapılan 2 . ve 3 . grup buzağıların klinik ve laboratuvar bulgularındaki iyileşmenin daha belirgin olduğu tespit edildi. Intranazal kateter ile oksijen uygulamanın maske ile uygulamaya göre daha etkili olduğu belirlendi. Sonuç olarak buzağılarda solunum sistemi hastalıklarında rutin tedaviyle birlikte oksijen tedavisi uygulanmasının arteriyel ve venöz kan gazları üzerine etkili olduğu ve solunum güçlüğü olan buzağıların klinik iyileşmesinde faydalı olduğu kanısına varıldı.

Anahtar Kelimeler: Buzağı, kan gazları, oksijen tedavisi, solunum güçlüğü

\section{Effects of Different Oxygen Application Methods on Arterial and Venous Blood Gases in Calves with} Respiratory System Disease

\section{Abstract}

The purpose of this study was to evaluate the effect of oxygen applications by mask and intranasal catheter in addition to routine respiratory system treatment on clinical and hematological findings as well as arterial and venous blood gases in calves with respiratory system disease that require oxygen therapy according to blood gases analyses. The material of this study consisted of 18 calves. Subsequent to clinical examinations, calves with respiratory system disease that require oxygen therapy according to blood ga ses analyses were included to the study. Calves were separated into 3 groups as $1^{\text {st }}$ group (control), $2^{\text {nd }}$ group (mask) and $3^{\text {rd }}$ group (intranasal catheter). $1^{\text {st }}$ group received routine respiratory system disease treatment, $2^{\text {nd }}$ group received routine respiratory system disease treatment as well as oxygen therapy by mask, $3^{\text {rd }}$ group received routine respiratory system disease treatment as well as oxygen therapy by intranasal catheter. For blood gas analyses, arteriol and venous blood samples were obtained in $0^{\text {th }}, 3^{\text {rd }}, 5^{\text {th }}$ and $24^{\text {th }}$ hours of the study. In calves with dyspnea, statistical differences were observed in venous and arterial $\mathrm{pH}, \mathrm{pCO}_{2}, \mathrm{pO}_{2}$, lactate, $\mathrm{sO}_{2}$ and respiratory rate within group comparisons. In $1^{\text {st }}$ group these parameters did not have apparent change, however, particularly $\mathrm{pCO}_{2}$ levels became normal eventually in $2^{\text {rd }}$ and $3^{\text {rd }}$ group that received oxygen therapy. Additionally, in $2^{\text {rd }}$ and $3^{\text {rd }}$ groups, while lactate concentrations decreased, $\mathrm{sO}_{2}$ and $\mathrm{pO}_{2}$ concentrations had increased. Recovery was apparent in clinical and laboratory findings apparent in calves that received oxygen therapy. It is also observed that while administering oxygen, intranasal catether application was more efficient than applying with mask on blood gases. As a result, it is concluded that applying oxygen therapy in addition to routine respiratory disease therapy on calves with respiratory disease was efficient on arterial and venous blood gases and this application is useful in clinical recovery.

Key Words: Calf, blood gases, oxygen therapy, dyspnea

\section{GiRiş}

Sığırlarda solunum sistemi hastalıkları her yaş grubunda yaygın olarak görülmesine rağmen, özellikle yenidoğan buzağılarda daha fazla görülmektedir $(1,2)$. Neonatal dönemde (0-
28 günlük) ortaya çıkan solunum sistemi hastalıklarına bağı olarak ortaya çıkan gelişme geriliği veya buzağı kayıpları büyük ekonomik kayıplara yol açmaktadır $(2,3)$.

Solunum sistemi hastalıklarında kan gazı analizlerinin yapılması, hastalıkların değerlendirilmesi açısından son derece 
önemlidir (4). Asit-baz dengesi ve solunumun değerlendirmesinde arteriyel ve venöz kan gazı analizleri yapılmaktadır. Buzağılarda solunum güçlüğüne yol açan hastalıklarda etiyolojik tedavilerin yanı sıra destekleyici tedavilerin de yapılması büyük önem arz etmektedir. Destekleyici tedaviler arasında yer alan oksijen tedavisi her ne kadar buzağılarda yaygın olarak kullanımıyorsa da, solunum güçlüğüne yol açan durumlarda oksijen tedavisinin önemli olduğu bildirilmiştir $(1,5)$. Bununla birlikte solunum sistemi hastalıklarında oksijen tedavisinin kan gazı parametreleri üzerinde önemli etkileri olduğu ve klinik olarak oksijen tedavisinin önemli olduğu bildirilmiştir (6).

Bu çalışma, solunum sistemi hastalığına sahip ve yapılan kan gazları analizlerine göre oksijen tedavisi ihtiyacı olan buzağılarda, rutin solunum sistemi tedavisiyle birlikte maske ve intranazal kateter ile oksijen uygulamalarının arteriyel ve venöz kan gazları üzerine etkilerinin belirlenmesi amacıyla yapıldı.

\section{MATERYAL VE METOT}

Çalışmanın materyalini, Van Yüzüncü Yıl Üniversitesi Veteriner Fakültesi kliniklerine getirilen, farklı yaş (1 gün-3 aylık), ırk ve cinsiyete sahip 18 buzağı oluşturdu. Klinik muayeneler sonucu solunum sistemi problemi olan ve kan gazları sonuçlarına göre oksijen tedavisine ihtiyaç duyan [oksijen saturasyonu $\left(\mathrm{SaO}_{2}\right)=<\% 90$, parsiyel arteriyel oksijen basıncı $\left(\mathrm{PaO}_{2}\right)$ $=<60 \mathrm{mmHg}$, parsiyel venöz oksijen basıncı $\left(\mathrm{PvO}_{2}\right)=<40$ $\mathrm{mmHg}$ )] buzağılar çalışmaya dâhil edildi.

Buzağılar 3 gruba ( $n=6)$ ayrıldı. 1. grup (Kontrol), 2. grup (Maske) ve 3. grup (Intranazal kateter) grubu olarak belirlendi. 1. grup hayvanlara rutin solunum sistemi tedavisi, 2. grup hayvanlara rutin solunum sistemi tedavisinin yanı sıra maske ile oksijen tedavisi, 3. grup hayvanlara ise rutin solunum sistemi tedavisine ilave olarak intranazal kateter ile oksijen verildi. Hasta hayvanlara rutin tedavi amacıyla linkomisin+spektinomisin kombinasyonu ( $15 \mathrm{mg} / \mathrm{kg}$ dozda, 5 gün süreyle iM), C vitamini ( $20 \mathrm{mg} / \mathrm{kg}$ dozda, 5 gün süreyle iM), meloksikam ( $0.5 \mathrm{mg} / \mathrm{kg}$ tek doz SC) ve A, D, E vitamin kombinasyonları (1 ml/50 kg CA hesabıyla tek doz iM - Ademin ${ }^{\circledR}$, CEVA, Türkiye) uygulandı. 2. grup ve 3. gruptaki buzağılara 46 L/dk akış hızıyla, yöntemine uygun olarak yerleştirilen maske ve intranazal kateter ile $30 \mathrm{dk}$ süreyle oksijen (Taşınabilir oksijen konsantratörü-Health Time OC-5) uygulandı. 10 dakika ara verilip daha sonra oksijen uygulaması tekrarlandı, bu uygulamaya 3 saat süreyle devam edildi. Yüz maskesi buzağıların ağız ve burnunu tam olarak içine alacak şekilde yerleştirildi. Buzağılarda intranazal kateter yerleştirilmesinden önce nemlendirme amacıyla burun içine $\% 0.9 \mathrm{NaCl}$ solüsyonu verildi. İntranazal kateter burun boşluğu ile gözün dış açısı arasındaki mesafenin $1 / 3^{\prime}$ ine kadar itildi ve baş bölgesine sabitlendi.

Buzağılardan 0., 3., 5 ve 24. saatlerde venöz kan gazları analizleri için vena jugularis'ten heparinli enjektöre $(2.5 \mathrm{ml})$, arteriyel kan gazları analizleri için ise arteria auricularis caudalis'ten heparinli insülin enjektörüne $(1 \mathrm{ml})$ kan örnekleri alındı ve hemen laboratuvara ulaştırılarak ölçümleri yapıldı. Alınan venöz ve arteriyel kan örneklerinden $\mathrm{pH}, \mathrm{pCO}_{2}, \mathrm{pO}_{2}$, laktat, $\mathrm{SO}_{2}, \mathrm{Na}, \mathrm{K}, \mathrm{Cl}$ ve Ca parametreleri kan gazları cihazı (ABL-80 Basic kan gazları cihazı) ile tespit edildi.

Elde edilen verilerin istatistiksel analizinde SPSS (for Windows 23.0 E. version) istatistik paket programı kullanıldı.
Grupların kendi içerisinde farklı zamanlardaki ortalamalarının karşılaştırılmasında Paired-Samples T testi kullanıldı. Tüm grupların aynı saatlerdeki ortalamalarının karşılaştırılmasında oneway anova (tek yönlü varyans analizi) testi kullanıldı. Tüm grupların aynı saatlerindeki ortalamalar arasındaki farklılıkların önem kontrolü Duncan çoklu karşılaştırma testiyle yapıldı. Tüm analizlerde anlamlılık düzeyi 0.05 olarak kabul edilmiştir.

\section{BULGULAR}

Buzağıların arteriyel ve venöz kan örneklerinden (0., 3., 5. ve 24. saatler) $\mathrm{pH}, \mathrm{pCO}_{2}, \mathrm{pO}_{2}$, laktat, $\mathrm{SO}_{2}, \mathrm{Na}, \mathrm{K}, \mathrm{Cl}$ ve Ca parametreleri tespit edildi. Çalışmanın tüm gruplarının (1., 2., 3. grup) farklı saatlerine (0., 3., 5., 24. saatler) ait $\mathrm{pH}, \mathrm{pCO}_{2}, \mathrm{pO}_{2}$, laktat, $\mathrm{SO}_{2}, \mathrm{Na}, \mathrm{K}, \mathrm{Cl}$ ve $\mathrm{Ca}$ değerleri ile bu değerlerin her grubun kendi içinde ve farklı grupların aynı saatlerine ait arteriyel (Tablo 1 ) ve venöz (Tablo 2 ) kan gazı değerlerinin istatistiksel karşılaştırmaları tablolarda verildi.

\section{TARTIŞMA VE SONUÇ}

Bu çalışmada, oksijen tedavisi ihtiyacı olan solunum sistemi hastalıklı buzağılarda, rutin solunum sistemi tedavisine ilave olarak maske ve intranazal kateter yöntemiyle oksijen uygulamasının arteriyel ve venöz kan gazları üzerine etkileri araştırıldı.

Yapılan çeşitli çalışmalarda $(1,6)$ farklı uygulama yolları ile oksijen verilmesinin hayvanlarda çeşitli avantaj ve dezavantajları olduğu bildirilmiştir. Bu bildirimlere paralel olarak bu çalışmada da, maskenin buzağılara rahat bir şekilde uygulanabildiği, ancak maskenin tutulması için bir yardımcıya ihtiyaç duyulduğu ve yüze tam olarak yerleştirilmesinde bazı hayvanlarda sorun yaşandığı tespit edildi. İntranazal kateter uygulamasının ise hayvanlar tarafından iyi tolere edildiği, herhangi bir yardımcıya ihtiyaç duyulmadığı ve uygulanmasının kolay olduğu, bu nedenle bu yöntemin maske ile oksijen vermeye göre daha pratik olduğu gözlemlendi. Rutin tedavi uygulanan 1. grup hayvanlarda 24 saatlik süre zarfında beden ısılarında azalma dışında, diğer klinik bulgularda önemli bir klinik iyileşmenin görülmediği, rutin tedaviye ilave olarak oksijen verilen 2 . ve 3 . grup hayvanlarda ise oksijen uygulanması ile birlikte klinik semptomların hafiflediği ve zamanla normale döndüğü belirlendi. Gözlemlerimize göre intranazal kateterle oksijen tedavisi yapılan 3. grup hayvanlarda iyileşme hızının 1. ve 2. gruptaki hayvanlardan daha iyi olduğu (24. saatte) belirlendi. Solunum sistemi hastalıklarında oksijen tedavisinin klinik iyileşmeye yardımcı olduğu $(1,6,7)$ bildirimleri, bizim bu bulgu ve tespitlerimizi destekler mahiyettedir. Brisville ve ark.'ları (8), buzağılarda solunum güçlüğü durumularında intranazal kateterle 1-15 L/dk akış hızında oksijen uygulanabileceğini, Bleul ve ark.'ları (6) ise intranazal kateter yöntemi ile 5-6 L/dk akış hızında oksijen uygulanabileceğini belirtmişlerdir. Yapılan bu çalışmada maske ve intranazal kateter yöntemleri ile 4-6 L/dk akış hızıyla oksijen uygulaması yapıldı. Destekleyici tedavide oksijen verilen gruplarda klinik bulgularda ve kan gazları değerlerindeki değişimlerinin daha iyi olduğunu ve oksijen verilmesinin yararlı olduğu belirlendi. Bu bulgular çeşitli araştırıcıların $(1,6,7,8)$ bildirimleriyle uyumlu bulundu. 
Tablo 1. Arteriyel kan gazı bulgularının gruplara ve saatlere göre istatistiksel karşılaştırmaları PARAMETRELER

\begin{tabular}{|c|c|c|c|c|c|c|c|c|c|c|}
\hline GRUPLAR & SAATLER & $\mathrm{pH}$ & $\mathrm{PCO}_{2}(\mathrm{mmHg})$ & $\mathrm{PO}_{2}(\mathrm{mmHg})$ & Laktat (mmol/L) & $\mathrm{SO}_{2}(\%)$ & $\mathrm{Na}(\mathrm{mmol} / \mathrm{L})$ & $\mathrm{K}(\mathrm{mmol} / \mathrm{L})$ & $\mathrm{Cl}(\mathrm{mmol} / \mathrm{L})$ & $\mathrm{Ca}(\mathrm{mmol} / \mathrm{L})$ \\
\hline \multirow{4}{*}{ 1. Grup } & 0. Saat & $7.44 \pm 0.02$ & $32.85 \pm 1.17$ & $40.16 \pm 1.55^{b, A}$ & $1.91 \pm 0.26$ & $75.48 \pm 3.58$ & $136.66 \pm 0.76$ & $4.84 \pm 0.31$ & $99.00 \pm 1.26^{a}$ & $1.24 \pm 0.06^{\mathrm{ab}}$ \\
\hline & 3. Saat & $7.42 \pm 0.01$ & $33.58 \pm 1.15$ & $40.66 \pm 2.04^{\mathrm{ab}}$ & $1.63 \pm 0.38$ & $74.58 \pm 3.23$ & $137.00 \pm 0.77$ & $4.93 \pm 0.21$ & $99.16 \pm 1.04^{\mathrm{ab}}$ & $1.27 \pm 0.06^{\mathrm{a}}$ \\
\hline & 5. Saat & $7.42 \pm 0.01$ & $32.96 \pm 1.49$ & $39.33 \pm 6.02^{\mathrm{ab}}$ & $1.40 \pm 0.08$ & $64.95 \pm 8.24$ & $136.50 \pm 0.22$ & $5.44 \pm 0.20^{\mathrm{A}}$ & $99.66 \pm 1.05^{b}$ & $1.21 \pm 0.07^{b}$ \\
\hline & 24. Saat & $7.43 \pm 0.01^{\mathrm{A}}$ & $32.36 \pm 3.39$ & $41.83 \pm 5.91^{\mathrm{a}}$ & $2.00 \pm 0.39$ & $67.90 \pm 8.46$ & $136.00 \pm 1.12$ & $4.81 \pm 0.29$ & $101.00 \pm 0.36^{\mathrm{ab}}$ & $1.17 \pm 0.05^{b}$ \\
\hline \multirow{4}{*}{ 2. Grup } & 0 . Saat & $7.46 \pm 0.18$ & $36.23 \pm 3.32^{f}$ & $34.17 \pm 1.58^{\mathrm{e}, \mathrm{B}}$ & $2.03 \pm 0.16^{e}$ & $67.70 \pm 2.82^{\mathrm{ef}}$ & $136.00 \pm 1.71$ & $4.34 \pm 0.20$ & $97.83 \pm 2.34$ & $1.14 \pm 0.07$ \\
\hline & 3. Saat & $7.46 \pm 0.17$ & $39.28 \pm 2.85^{\mathrm{e}}$ & $34.50 \pm 2.86^{\mathrm{e}}$ & $1.33 \pm 0.17^{f}$ & $67.08 \pm 5.11^{f}$ & $135.33 \pm 0.76$ & $4.53 \pm 0.24$ & $96.17 \pm 1.78$ & $1.20 \pm 0.09$ \\
\hline & 5. Saat & $7.44 \pm 0.18$ & $40.70 \pm 3.85^{e}$ & $31.00 \pm 3.10^{f}$ & $1.45 \pm 0.17^{f}$ & $59.95 \pm 6.56^{e}$ & $136.00 \pm 0.63$ & $4.36 \pm 0.20^{c}$ & $97.67 \pm 1.58$ & $1.18 \pm 0.08$ \\
\hline & 24. Saat & $7.45 \pm 0.24^{\mathrm{AB}}$ & $37.20 \pm 2.13^{f}$ & $38.50 \pm 1.98^{e}$ & $1.32 \pm 0.07^{f}$ & $72.53 \pm 3.03^{e}$ & $137.67 \pm 1.36$ & $4.60 \pm 0.20$ & $98.00 \pm 2.39$ & $1.17 \pm 0.01$ \\
\hline \multirow{4}{*}{ 3. Grup } & 0. Saat & $7.48 \pm 0.01$ & $36.92 \pm 1.56$ & $24.67 \pm 2.39 \mathrm{~g}, \mathrm{C}$ & $2.87 \pm 0.58^{\mathrm{g}}$ & $50.37 \pm 6.68$ & $135.83 \pm 0.87$ & $4.97 \pm 0.26^{g}$ & $97.00 \pm 1.29$ & $1.18 \pm 0.04^{\mathrm{h}}$ \\
\hline & 3. Saat & $7.46 \pm 0.02$ & $40.98 \pm 3.36$ & $34.33 \pm 3.99 \mathrm{gh}$ & $1.95 \pm 0.69 \mathrm{gh}$ & $66.00 \pm 7.99$ & $137.33 \pm 0.56$ & $4.76 \pm 0.09^{g h}$ & $97.00 \pm 1.03$ & $1.25 \pm 0.02^{h}$ \\
\hline & 5. Saat & $7.47 \pm 0.01$ & $39.48 \pm 1.31$ & $30.17 \pm 2.30^{\mathrm{hj}}$ & $1.95 \pm 0.41^{\mathrm{gh}}$ & $68.85 \pm 5.90$ & $138.00 \pm 1.00$ & $4.72 \pm 0.11^{\mathrm{h}, \mathrm{B}}$ & $97.83 \pm 1.08$ & $1.24 \pm 0.01^{\mathrm{h}}$ \\
\hline & 24. Saat & $7.49 \pm 0.01^{B}$ & $40.90 \pm 1.99$ & $36.50 \pm 3.78^{\mathrm{g}}$ & $1.63 \pm 0.40^{\mathrm{h}}$ & $71.18 \pm 5.54$ & $138.17 \pm 0.79$ & $4.89 \pm 0.06^{\mathrm{gh}}$ & $97.17 \pm 1.25$ & $1.30 \pm 0.01^{\mathrm{g}}$ \\
\hline
\end{tabular}

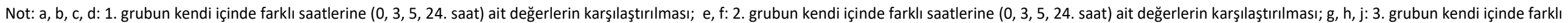
saatlerine $(0,3,5,24$. saat) ait değerlerin karşıllaşıııı Iması; A, B, C: 1., 2., 3., gruplara ait aynı saatlerdeki değerlerin karşslaştırılması

Tablo 2. Venöz kan gazı bulgularının gruplara ve saatlere göre istatistiksel karşılaştırmaları

\begin{tabular}{|c|c|c|c|c|c|c|c|c|c|c|}
\hline \multirow[b]{2}{*}{ GRUPLAR } & \multirow[b]{2}{*}{ SAATLER } & \multicolumn{9}{|c|}{ PARAMETRELER } \\
\hline & & $\mathrm{pH}$ & $\mathrm{PCO}_{2}(\mathrm{mmHg})$ & $\mathrm{PO}_{2}(\mathrm{mmHg})$ & Laktat (mmol/L) & $\mathrm{SO}_{2}(\%)$ & $\mathrm{Na}$ (mmol/L) & $\mathrm{K}(\mathrm{mmol} / \mathrm{L})$ & $\mathrm{Cl}(\mathrm{mmol} / \mathrm{L})$ & $\mathrm{Ca}(\mathrm{mmol} / \mathrm{L})$ \\
\hline \multirow{4}{*}{ 1. Grup } & 0. Saat & $7.44 \pm 0.19^{a}$ & $36.65 \pm 2.74^{a}$ & $29.83 \pm 1.35^{\mathrm{a}, \mathrm{A}}$ & $1.88 \pm 0.24$ & $59.26 \pm 3.97$ & $135.16 \pm 2.13$ & $4.59 \pm 0.34$ & $96.16 \pm 2.53^{a b c}$ & $1.20 \pm 0.06$ \\
\hline & 3. Saat & $7.41 \pm 0.19^{\mathrm{ab}}$ & $40.18 \pm 2.81^{b}$ & $27.33 \pm 1.40^{\mathrm{b}}$ & $1.48 \pm 0.40$ & $51.53 \pm 3.78$ & $135.66 \pm 2.10$ & $4.54 \pm 0.19$ & $96.16 \pm 2.71^{\mathrm{a}}$ & $1.23 \pm 0.04$ \\
\hline & 5. Saat & $7.40 \pm 0.13^{\mathrm{b}, \mathrm{B}}$ & $41.53 \pm 40^{\mathrm{ab}}$ & $28.33 \pm 1.78^{a b}$ & $1.08 \pm 0.07$ & $56.33 \pm 2.13$ & $135.50 \pm 2.18$ & $4.73 \pm 0.34$ & $97.16 \pm 2.57^{b c}$ & $1.19 \pm 0.06$ \\
\hline & 24. Saat & $7.43 \pm 0.01^{b}$ & $39.91 \pm 3.00^{\mathrm{b}}$ & $30.50 \pm 1.70^{\mathrm{ab}}$ & $1.86 \pm 0.35$ & $56.68 \pm 4.22$ & $136.16 \pm 2.50$ & $4.41 \pm 0.18$ & $97.50 \pm 2.56^{c}$ & $1.22 \pm 0.06$ \\
\hline \multirow{4}{*}{ 2. Grup } & 0. Saat & $7.46 \pm 0.21$ & $39.53 \pm 2.77$ & $27.67 \pm 1.41^{\mathrm{e}, \mathrm{A}}$ & $1.60 \pm 0.23^{e}$ & $55.30 \pm 2.99^{f}$ & $137.00 \pm 1.03$ & $4.27 \pm 0.17^{f}$ & $96.17 \pm 1.51$ & $1,20 \pm 0.08$ \\
\hline & 3. Saat & $7.46 \pm 0.22$ & $38.40 \pm 4.54$ & $30.50 \pm 2.63^{e f}$ & $1.37 \pm 0.22^{\mathrm{ef}}$ & $61.00 \pm 6.56^{e}$ & $136.17 \pm 0.70$ & $4.37 \pm 0.20^{\mathrm{e}}$ & $96.00 \pm 1.71$ & $1.19 \pm 0.08$ \\
\hline & 5. Saat & $7.46 \pm 0.01^{\mathrm{A}}$ & $38.87 \pm 2.14$ & $28.00 \pm 2.90^{e f}$ & $1.32 \pm 0.17^{\mathrm{e}}$ & $55.38 \pm 6.42^{f}$ & $136.50 \pm 0.67$ & $4.26 \pm 0.10^{f}$ & $97.33 \pm 1.69$ & $1.20 \pm 0.07$ \\
\hline & 24. Saat & $7.46 \pm 0.23$ & $39.90 \pm 1.68$ & $31.17 \pm 1.17^{\mathrm{e}}$ & $0.95 \pm 0.07^{f}$ & $62.92 \pm 2.31^{\mathrm{e}}$ & $136.67 \pm 0.92$ & $4.38 \pm 0.14^{\mathrm{e}}$ & $97.33 \pm 1.65$ & $1.19 \pm 0.08$ \\
\hline \multirow{4}{*}{ 3. Grup } & 0 . Saat & $7.43 \pm 0.02^{g}$ & $46.32 \pm 3.17$ & $23.00 \pm 1.55^{\mathrm{g}, \mathrm{B}}$ & $2.13 \pm 0.49$ & $41.17 \pm 4.34$ & $137.33 \pm 0.56^{\mathrm{h}}$ & $4.60 \pm 0.09$ & $95.50 \pm 1.20^{\mathrm{h}}$ & $1.25 \pm 0.01^{\mathrm{h}}$ \\
\hline & 3. Saat & $7.45 \pm 0.01^{h}$ & $44.57 \pm 1.81$ & $33.67 \pm 5.67^{\mathrm{gh}}$ & $1.70 \pm 0.36$ & $60.45 \pm 8.81$ & $138.00 \pm 0.82^{\mathrm{g}}$ & $4.42 \pm 0.01$ & $96.67 \pm 0.84^{g}$ & $1.28 \pm 0.01^{\mathrm{gh}}$ \\
\hline & 5. Saat & $7.44 \pm 001^{\mathrm{h}, \mathrm{B}}$ & $44.95 \pm 2.43$ & $26.00 \pm 2.34 \mathrm{~g}$ & $1.83 \pm 0.37$ & $48.87 \pm 5.50$ & $138.50 \pm 0.56^{g}$ & $4.49 \pm 0.13$ & $97.00 \pm 1.10^{\mathrm{g}}$ & $1.25 \pm 0.01^{\mathrm{h}}$ \\
\hline & 24. Saat & $7.48 \pm 0.01^{h}$ & $42.10 \pm 2.29$ & $26.67 \pm 1.91^{\mathrm{h}}$ & $1.58 \pm 0.39$ & $52.90 \pm 4.40$ & $139.50 \pm 1.06^{\mathrm{g}}$ & $4.72 \pm 0.05$ & $97.00 \pm 1.15^{\mathrm{gh}}$ & $1.32 \pm 0.02^{\mathrm{g}}$ \\
\hline
\end{tabular}

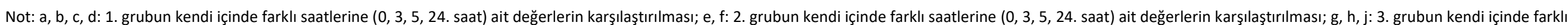
saatlerine (0, 3, 5, 24. saat) ait değerlerin karşılaştııı Iması; A, B, C: 1., 2., 3., gruplara ait aynı saatlerdeki değerlerin karşıllaştııılması 
Yapılan çalışmalarda $(5,8,9)$ solunum güçlüğü olan hayvanlarda kan gazları değerlerinde çeşitli değişimlerin olduğu ve bu değişimlerin izlenmesinin hastalığın tanı, tedavi ve prognozu için önemli olduğu bildirilmiştir. Solunum güçlüğü olan buzağılarda oksijen tedavisi ve kan gazı parametreleri üzerine etkileriyle ilgili yapılan çalışmalarda $(1,6,7,9)$, solunum güçlüğü olan buzağılarda kan gazlarından arteriyel ve venöz $\mathrm{kan} \mathrm{pO}_{2}, \mathrm{SO}_{2}$ düzeylerinde azalma, $\mathrm{pCO}_{2}$ ve laktat düzeylerinde artış şekillendiği ve yapılan oksijen tedavileri ile bu parametrelerde düzelme olduğu bildirilmiştir. Ok ve Birdane (10), prematüre buzağılarda venöz kan $\mathrm{pH}, \mathrm{HCO}_{3}, \mathrm{pO}_{2}$ ve $\mathrm{SO}_{2}$ değerlerinin düşük, $\mathrm{pCO}_{2}$ değerinin ise yüksek olduğunu, $\mathrm{pO}_{2}{ }^{\prime}$ deki azalmanın doku hipoksisine, $\mathrm{pCO}_{2}{ }^{\prime}$ deki artışın ise respiratorik asidozise bağlı olduğunu bildirmişlerdir. Bleul ve ark.'ları (6), buzağılarda intranazal oksijen uygulamasının $\mathrm{pO}_{2}, \mathrm{SO}_{2}$ ve $\mathrm{pH}$ değerlerini arttırdığını bildirmişlerdir.

Solunum güçlüğü olan hayvanlarda respiratorik asidoz veya respiratorik alkaloz tablosu gelişebilmektedir. Solunum güçlüğü olan hayvanlarda kan pH değerinde değişimler meydana gelmekte, $\mathrm{pH}$ değerinin azalmasına asidemi, artmasına ise alkalemi denilmektedir. Solunum güçlüğü sonucu vücut$\tan \mathrm{CO}_{2}$ atılımının engellenmesi ve $\mathrm{CO}_{2}$ birikimine bağı olarak respiratorik asidozis oluşmaktadır. Bu durumda kan arter $\mathrm{pH}$ değeri $7.35^{\prime}$ in altında ve kan $\mathrm{pCO}_{2}$ değeri 45 mmHg'nin üzerinde ölçülmektedir $(11,12,13)$. Solunum merkezinin uyarılması sonucu alveolar hiperventilasyon ile kanda $\mathrm{pCO}_{2}$ değeri azalmakta ve kan $\mathrm{pH}$ değeri yükselmektedir. Ortaya çıkan bu tabloya respiratörik alkaloz denilmektedir $(11,12$, $13,14)$. Bu çalışmada da oksijen verilmeyen 1 . grup buzağıların arter $\mathrm{pH}$ değerlerinin normal sınırlarda olduğu, ven $\mathrm{pH}$ değerlerinin ise sadece 0 . ve 24 . saatlerde normal sınırların üzerinde olduğu tespit edildi. Oksijen verilen 2. ve 3. grup buzağıların arter ve ven $\mathrm{pH}$ değerlerinin tedavi öncesi $(0$. saat) yüksek olduğu, oksijen uygulaması ile birlikte $\mathrm{pH}$ değerlerinin azalarak normal değerlere ulaştığı belirlendi. Bu çalışmada $\mathrm{pH}$ değerlerindeki artışın buzağılarda görülen hiperventilayona bağlı gelişen respiratorik alkaloz varlığını desteklemektedir. Nitekim çalışma grubu hayvanlarda $\mathrm{pCO}_{2}$ düzeylerinde düşüşlerin olması da hiperventilasyon ve respiratorik alkaloz varlığını desteklemektedir. Bu durum bazı araştırmacıların $(11,13,14)$ bildirimleriyle uyumlu bulunmuştur. Respiratorik alkaloz durumlarında yükselen kan $\mathrm{pH}^{\prime}$ sını düşürmek amacıyla, idrarla $\mathrm{H}^{+}$iyonu atılımı azalmakta, $\mathrm{HCO}_{3}{ }^{-}$iyonu atılımı artmaktadır. Solunum güçlüğü durumlarında dokularda hipoksi meydana gelmektedir. Hipoksinin olumsuz etkileri oksijen verilmesiyle azaltılmakta ve dokulara yeterli oksijen ulaşmasına bağlı olarak vücutta metabolik faaliyetler artmaktadır. Bu durumda metabolik faaliyetlerin artmasıyla birlikte vücutta karbondioksit düzeyi artmaktadır (2). Bu çaIsşmada da oksijen uygulaması yapılan 2. ve 3. grup buzağılarda, $\mathrm{pH}$ değerlerinde belirlenen azalmaların, verilen oksijenin dokulara ulaşması ile birlikte dokulardaki hipoksinin azalması ve metabolik faaliyetler sonucu artan $\mathrm{CO}_{2}$ kaynaklı olabileceğini düşünmekteyiz.

Solunum güçlüğü olan buzağılarda $\mathrm{pCO}_{2}$ 'nin ölçümü oldukça önemlidir. $\mathrm{CO}_{2}{ }^{\prime}$ in alveollerden diffüzyonu oksijenden daha fazla olmakta ve sadece akciğerler tarafından vücuttan uzaklaştırılmaktadır. $\mathrm{Bu}$ yüzden hastalarda $\mathrm{CO}_{2}$ retensiyonunun olması veya aşırı atılması akciğerin bazı nedenlere bağı olarak fonksiyon gösteremediğinin kanıtı olarak kabul edilmektedir $(6,9)$. Bu çalışmada 1 . grup buzağıların 0 . saat arter ve ven $\mathrm{pCO}_{2}$ değerlerinin normal sınırların altında olduğu, tedaviye rağmen bu gruptaki hayvanlarda 24 . saatte de bu durumun değişmediği ve normal sınırların altında kaldığı gözlendi. Oksijen verilen 2. grupta arter $\mathrm{pCO}_{2}$ değerlerinin 0 . ve 24. saatlerde normal değerlerin alt sınırında olduğu, ancak oksijen tedavisi yapılan saatlerde (3. ve 5. saat) arter $\mathrm{pCO}_{2}$ değerlerinin normal değerler arasında olduğu belirlendi. Intranazal kateter ile oksijen verilen 3 . grupta ise arter ve ven $\mathrm{pCO}_{2}$ değerlerinin normal sınırlar arasında olduğu tespit edildi. Nitekim buzağılarda oksijen tedavisi hakkında yapılan çalışmalarda genellikle prematüre buzağılarda oksijen tedavisi uygulaması yapıldığı, prematüre buzağılarda $\mathrm{pH}$ değerlerinin düşük, $\mathrm{pCO}_{2}$ değerlerinin ise yüksek olduğu, bu durumun buzağılarda hipoventilasyon ve respiratorik asidozisten kaynaklı olduğu bildirilmiştir $(6,8,9$, $15,16)$. Bu çalışmada ise 1 . ve 2 . grup hayvanlarda $\mathrm{pCO}_{2}$ değerlerinin alt sınırlarda olması, bazı araştırıcıların $(11,13,14)$ bildirimlerine paralel olarak, $\mathrm{pCO}_{2}$ değerlerindeki azalmaların solunum güçlüğü olan buzağılarda hiperventilasyon ve respiratorik alkaloz varlığına bağlı olabileceğini göstermektedir. Bu çalışmada oksijen uygulaması yapılan 2. grup buzağılarda, $\mathrm{pCO}_{2}$ değerlerinde belirlenen artışların, verilen oksijenin dokulara ulaşması ile birlikte dokulardaki hipoksinin azalması ve metabolik faaliyetler sonucu artan $\mathrm{CO}_{2}$ kaynaklı olabileceğini düşünmekteyiz. Oksijen uygulaması yapılan 3 . grup buzağılarda ise, $\mathrm{pCO}_{2}$ değerlerinin normal sınırlar arasında olduğu $\mathrm{pCO}_{2}$ değerlerinde bireysel farklılıklara bağlı olarak değişim olmadığı düşünülmektedir.

Oksijenizasyon durumu hakkında bilgi için arteriyel veya venöz $\mathrm{pO}_{2}$ 'nin değerlendirilmesinin önemli olduğu bildirilmiştir $(9,17)$. Çalışmalarda solunum güçlüğüne bağlı olarak $\mathrm{pO}_{2}^{\prime}$ nın azaldığı, arter $\mathrm{pO}_{2}^{\prime}$ nın 60 mmHg, ven $\mathrm{pO}_{2}^{\prime}$ nın ise $40 \mathrm{mmHg}$ 'nin altında olmasının solunum güçlüğüne işaret olduğu ve bu hastalarda oksijen tedavisinin yapılması gerektiği bildirilmektedir $(1,15)$. Bleul ve ark.,'ları $(6)$, solunum güçlüğü olan buzağılarda arteriyel $\mathrm{pO}_{2}{ }^{\prime}$ nin $45 \mathrm{mmHg}$ değerinin altında olduğunu bildirmiştir. Venöz kanda $\mathrm{pO}_{2}$ düzeyinin 40 $\mathrm{mmHg}$ değerinin altında olmasının, organizmada yetersiz oksijen dağılımını gösterdiği bildirilmiştir (15). Bu çalışmada da kan gazı analiz sonuçlarına göre $\mathrm{PaO}_{2}$ değeri $60 \mathrm{mmHg}$ ve $\mathrm{PvO}_{2}$ değeri 40 mmHg'nin altında ölçülen buzağılar çalışmaya alındı. Brisville ve ark.'ları (8), solunum güçlüğü olan buzağılarda intranazal kateterle 1-15 L/dk akış hızında 6 saat boyunca oksijen uygulamasının arter $\mathrm{pO}_{2}$ değerini 80 mmHg'nın üzerinde bir değere ulaştırdığını belirlemişlerdir. Poulsen ve McGuirk (15), yenidoğan buzağılarda solunum güçlüğü durumunda oksijen verilmesiyle arter ve ven $\mathrm{pO}_{2}$ değerinin artığını, Paşa (1) solunum güçlüğü olan buzağılarda venöz $\mathrm{pO}_{2}$ değerinin düşük olduğunu, oksijen verilmesiyle bu değerin yükseldiğini bildirmiştir.

Yapılan bu çalışmada da kan gazları analizlerine göre tüm gruplardaki buzağılarda tedavi öncesi (0. saat) arter $\mathrm{pO}_{2}$ değerleri $<40 \mathrm{mmHg}$ ve venöz $\mathrm{pO}_{2}$ değerleri $<23 \mathrm{mmHg}$ 'den düşük bulunmuştur. Bu da tüm hayvanlarda solunum güçlüğü olduğunu ve oksijen verilmesi gerektiğini göstermiştir. 
Çalışmada her üç grup hayvanlara ait arter ve ven $\mathrm{pO}_{2}$ değerleri azalma göstermiş, uygulanan tedaviler sonrasında değişen derecelerde artışlar olduğu görülmüştür. 1. grup hayvanlarla karşılaştırıldığında oksijen verilen 2. ve 3. grup hayvanlarda $\mathrm{pO}_{2}$ değerlerindeki artışlar daha bariz görülmüştür. Oksijen verilen 2 . grup hayvanlara nazaran 3 grup hayvanlarda $\mathrm{pO}_{2}$ değerinde ortalama ve bireysel değerlerdeki artışlar daha bariz olarak gözlenmiştir. Bu çalışmada elde edilen arter $\mathrm{pO}_{2}$ sonuçları Bluel ve ark., (6)'in yaptığı çalışmanın sonuçlarıyla, venöz $\mathrm{pO}_{2}$ sonuçları ise Paşa (1)'nın yaptığı çaIışma sonuçlarıyla paralellik arz etmektedir. Ayrıca oksijen tedavisi uygulanan gruplarda (2. ve 3. grup); oksijen verilmeye başlandıktan sonra $\mathrm{pO}_{2}$ değerlerinde artış olması birçok araştırıcının $(1,6,7,8,10)$ bildirimleriyle paralellik göstermektedir. Çalışmada oksijen verilmesi esnasında $\mathrm{pO}_{2}$ değerinde artma görülmesi, oksijen kesildikten sonra ise $\mathrm{pO}_{2}$ değerlerinde düşme görülmesi araştırıcıların $(18,19)$ belirttiği gibi kan $\mathrm{pO}_{2}$ değerinin hemoglobinin oksijeni bağlama ve dokularda oksijeni serbest bırakma yeteneği ile ilişkili olabileceği görüşündeyiz.

Buzağılarda akciğer fonksiyonun değerlendirilmesi için kullanılan diğer bir parametre $\mathrm{SO}_{2}$ 'dir. Arterdeki normal değeri \%95-97, vendeki ise \%55-70 civarındadır (20). Solunum güçlüğü olan hayvanlarda $\mathrm{SO}_{2}$ değerindeki düşüşün alveollerde oksijen geçişinin engellenmesinden kaynaklı olduğu bildirilmiştir (19). Uysteprusyt ve ark.'Iarı (21), yenidoğan buzağılarda sağlıklı buzağıların arter $\mathrm{SO}_{2}$ değerinin \%81-93 arasında olması gerektiğini ileri sürmüşlerdir. Bleul ve ark.'ları (22), yeni doğan buzağılarda arter $\mathrm{SO}_{2}$ düzeyini \%76, venöz $\mathrm{SO}_{2}$ düzeyini ise \%34 olarak bildirmişlerdir. Yapılan çalışmalarda $(5,16)$, solunum güçlüğü durumlarında buzağılara destekleyici oksijen verilmesinin kanda düşmüş olan $\mathrm{SO}_{2}{ }^{\prime}$ nunu yükselttiğini bildirmiştir. Bleul ve ark.'ları (6), RDS'li buzağılarda intranazal oksijen uygulamasının ilk 24 saatinden sonra oksijen saturasyonunun (\%78 \pm 20 ) tedavi öncesine göre (\%53 \pm 20$)$ anlamlı derecede yüksek olduğunu bildirmişlerdir. Yapılan bu çalışmada tedavi öncesi (0. saat) arter $\mathrm{SO}_{2}$ değeri \%50-75 ve ven $\mathrm{SO}_{2}$ değeri \%41-59 arasında bulunmuştur. Solunum güçlüğü çeken hayvanlarda $\mathrm{SO}_{2}$ değerinin düşük bulunması araştırıcıların $(1,6,9,22)$ bildirimleriyle paralellik göstermektedir. Çalışmada oksijen verilmeyen 1 . gruptaki buzağıların 0. saatte ölçülen $\mathrm{SO}_{2}$ değerinin 24. saate kadar giderek düştüğü tespit edildi. Ancak oksijen verilen gruplardaki (2. ve 3 . grup) buzağılarda 0 . saatte ölçülen $\mathrm{SO}_{2}$ değerinin oksijen uygulamasıyla birlikte arttığı, 24. saatte önemli bir artış gösterdiği görüldü. Oksijen verilen gruplarda $\mathrm{SO}_{2}$ değerinin gittikçe artması, Paşa, (1)'nın bildirimleri ile uyumlu bulunmuştur.

Solunum güçlüğü durumlarında hipoksi nedeniyle kan laktat konsantrasyonu artmakta, bu da metabolik asidoza neden olmaktadır $(6,23)$. Laktat, solunum güçlüğünün tedavisinin etkinliğini belirlemede kullanılabilen önemli bir parametre olup, normal değeri 0.3-1.3 mmol/L'dir $(13,24)$. Laktatın $2 \mathrm{mmol} / \mathrm{L}$ altındaki değerleri klinik olarak önemli değilken, 2-4 mmol/L arasındaki değerleri klinik bir uyarı niteliğinde olmaktadır. Laktat değerinin $4 \mathrm{mmol} / \mathrm{L}^{\prime}$ nin üzerinde olması ise aneorobik metabolizmanın oluştuğunu, hücresel metabolizmanın ve oksijen taşınmasının bozulduğunun önemli bir göstergesi olduğu (9), laktat değerinin $\geq 10$
$\mathrm{mEq} / \mathrm{L}^{\prime}$ nin üzerinde olmasının mortalite oranını artırdığı bildirilmiştir $(10,13,23)$. Yapılan çalışmalarda $(25,26)$; buzağılarda solunum sistemi hastalıklarının ciddiyeti ile plazma laktat konsantrasyonu arasında önemli bir ilişki olduğunu ve laktat değerinin hastalığın mortalitesi için güvenilir prognostik bir gösterge olduğunu bildirmişlerdir. Yıldız (9)'da, buzağılarda kan laktat değerinin solunum güçlüğü için önemli bir parametre olduğunu bildirmiştir. Paşa (1), solunum güçlüğü olan buzağılarda kan laktat değerinin yüksek olduğunu, oksijen verilmesiyle bu değerin azaldığını ve normal sınırlara yaklaştığını bildirmiştir. Yapılan bu çalışmada tüm gruplardaki buzağıların tedavi öncesi (0. saatte) arteriyel laktat değeri 1.91-2.87 mmol/L ve venöz laktat değerinin 1.60-2.13 $\mathrm{mmol} / \mathrm{L}$ arasında olduğu tespit edildi. Oksijen uygulaması yapılmayan 1. gruptaki buzağılarda rutin tedaviye rağmen laktat değerinde önemli bir azalmanın olmadığı görüldü. Ancak oksijen verilen gruplarda (2. ve 3. grup) laktat değerinin normal sınırlara (<2 mmol/L) yaklaştığı görüldü. Oksijen uygulaması yapılan buzağılarda kan laktat değerinde azalmanın görülmesi ve normal düzeylere dönmesi araştırıcıların $(1,6,8$, $9,10)$ sonuçları ile uyumlu bulunmuştur. Bu çalışmada laktat değerinin çok yüksek olmaması, çalışmaya dâhil edilen buzağılarda genel olarak kan $\mathrm{pH}$ değerlerinin yüksek olması ve $\mathrm{pCO}_{2}$ değerlerinin düşük olması sonucu tespit edilen respiratörik alkalozdan kaynaklı olabileceğini düşünmekteyiz. Nitekim $\mathrm{pH}$ değerlerinin ve $\mathrm{pCO}_{2}$ değerlerinin yüksek olduğu respiratörik asidoz durumlarında laktat düzeyleri oldukça artış gösterebilmektedir.

Solunum güçlüğü bulunan buzağılarda kan gazlarında $\mathrm{Na}, \mathrm{K}, \mathrm{Cl}$ ve Ca parametrelerinin değerlendirildiği çalışmalar oldukça sınırlıdır. Ok ve ark.'ları (27), deneysel solunum yolu enfeksiyonu oluşturdukları kuzularda yaptıkları çalışmada venöz kan gazları analizinde $\mathrm{Na}$, $\mathrm{Ca}$ ve $\mathrm{K}$ değerlerinde herhangi bir farklılık saptamadıklarını bildirmişlerdir. Yapılan bu çalışmada da $\mathrm{Na}, \mathrm{K}, \mathrm{Cl}$ ve Ca düzeylerinde anlamlı bir fark bulunmadı.

Bu çalışmada maske ve intranazal kateter yöntemlerinin kullanılmasının basit, pratik ve komplikasyonlarının minimum düzeyde olduğu, ancak intranazal kateter ile oksijen uygulamasının tedavide daha etkili sonuçlar verdiği, rutin tedavi yapılmasına rağmen, oksijen uygulaması yapılmayan 1. gruptaki buzağılarda TÖ belirlenen $\mathrm{pCO}_{2}, \mathrm{SO}_{2}, \mathrm{pO}_{2}$ ve laktat değerlerinin genellikle değişmediği, ancak oksijen uygulaması yapılan 2. ve 3. gruplardaki buzağılarda arteriyel $\mathrm{pCO}_{2}$ değerlerinde genellikle bir artış, venöz $\mathrm{pCO}_{2}$ değerlerinde ise genel olarak bir değişim görülmediği, oksijen uygulaması yapılan gruplardaki buzağılarda laktat değerlerinin düştüğü, $\mathrm{SO}_{2}$ ile $\mathrm{pO}_{2}$ değerlerinin ise arttığı tespit edidi. Sonuç olarak solunum güçlüğü belirlenen buzağılarda oksijen uygulamalarının hastalarda klinik iyileşme ve kan gazı parametrelerinin düzelmesi üzerine etkili olduğu belirlenmiştir.

\section{TEŞEKKÜR}

Bu çalışma Van Yüzüncü Yıl Üniversitesi Bilimsel Araştırma Projeleri Başkanlığı tarafından "TYL-2019-7878" nolu proje olarak desteklenmiştir. Birinci isim yazarın aynı isimli yüksek lisans tezinden özetlenmiştir. 


\section{KAYNAKLAR}

1. Paşa S. (1998). Solunum Güçlüğü Çeken Buzağılarda Nasopharengial Tüp İle Oksijen Uygulamasının Bazı Kan Parametreleri ve Klinik Bulgular Üzerine Etkisi. Doktora tezi, Ankara Üniversitesi Sağlık Bilimleri Enstitüsü, Ankara.

2. Şentürk S. (2011). Sığırların Solunum Sistemi Hastalıkları. Özsan Matbaacılık, Bursa.

3. Güneş V, Onmaz AC, Ulusan M. (2013). Respiratory System Diseases in Neonatal Calves. Türkiye Klinikleri J Vet Sci. 4(1): 8694.

4. Atalan K, Edipoğlu is. (2014). Asit Baz Dengesi. Türk Yoğun Bakım Derg. 12:1-6.

5. Fahlman A. (2015). Oxygen Therapy. In: Zoo Animal and Wildlife Immobilization and Anesthesia. West G, Heard D, Caulkett N (eds). pp. 69-81. Blackwell Publishing. Ames.

6. Bleul UT, Bircher BM, Khan WK. (2008). Effect of Intranasal Oxygen Administration on Blood Gas Variables and Outcome in Neonatal Calves with Respiratory Distress Syndrome: 20 Cases (2004-2006). J Am Vet Med A. 233(2): 289-293.

7. Court BV, Dodman NH, Seeler DC. (1985). Oxygen Administration, Humidification and Aerosol. Vet Clin North Am. 15(5):1041-1059.

8. Brisville AC, Fecteau G, Boysen S, et al. (2011). Respiratory Disease in Neonatal Cloned Calves. J Vet Intern Med. 25(2): 373379.

9. Yıldız R. (2014). Respiratorik Distres Sendromlu Prematüre Buzağılarda Nebülizasyon Yöntemi ile Uygulanan Salbutamol, Flutikazon ve Furosemid Kombinasyonlarının Akciğer Fonksiyonu Üzerine Klinik Etkinliğinin Araştırılması. Doktora Tezi. Selçuk Üniversitesi Sağlık Bilimleri Enstitüsü, Konya.

10. Ok M, Birdane FM. (2000). Prematüre Buzağılarda Kan Asit-baz Dengesi, Bazı Kan Gazları ve Elektrolit Düzeyleri. Vet Bil Derg. 16(1): 147-150.

11. Yaman K. (1999). Fizyoloji. 4. Baskı, Ezgi Kitabevi, Bursa.

12. Aygencel G. (2014). Arter Kan Gazlarının Yorumlanması. Türk Kardiyol Dern Arş. 42(2):194-202.

13. İnangil G, Özkan S. (2018). Asit-baz Denge Bozukluğu. Yoğun Bakım Derg. 12(1): 8-17.

14. Coşkun A. (2016). Asit Baz Dengesi ve Arter Kan Gazlarının Yorumlanması Derman Tıbbi Yayıncılık, Sivas. DOI: 10.4328/DERMAN.4426.

15. Poulsen KP, McGuirk SM. (2009). Respiratory Disease of the Bovine Neonate. Vet Clin Food Anim. 25: 121-137.

16. Donnelly CG, Quinn CT, Nielsen SG, Raidal SL. (2016). Respiratory Support for Pharmacologically Induced Hypoxia in Neonatal Calves. Vet Med Intern. Article ID 2129362, 8 pages, DOI: https://doi.org/10.1155/2016/2129362.
17. Bleul U, Kahn W. (2008). Monitoring the Bovine Fetus during Stage II of Parturition Using Pulsoximetry. Theriogenology. 69(3):302-311.

18. Rose DP, Hudgson PD. (1983). Effect of Intranasal Oxygen Administration on Arterial Blood Gas and Acid Base Parameters in Spontaneously Delivered, Term Induced and Induced Prematüre Foals. Res Vet Sci. 34(2): 159-162.

19. Barrett KE, Barman SM, Boitano S, Brooks HL. (2011). Ganong'un Tıbbi Fizyolojisi. Çeviri Editörü: Gökbel H, 23. Baskı. Nobel Tıp Kitapevleri, Ankara.

20. Börekçi Ş, Umut S. (2011). Arter Kan Gazı Alma Tekniği, Analizi ve Yorumlanması. Türk Toraks Derg. 12:5-9.

21. Uystepruyst CH, Coghe J, Bureau F, Lekeux P. (2000). Evaluation of Accuracy of Pulse Oximetry in Newborn Calves. Vet J. 159(1): 71-76.

22. Bleul U, Lejeune B, Schwantag S, Kahn W. (2007). Blood Gas and Acid-base Analysis of Arterial Blood in 57 Newborn Calves. Vet Rec. 161: 688-691.

23. Sezer K, Duran Ş, Albay MK, Karakurum MÇ.(2013). Abomazum Deplasmanlı Sığırlarda D (-) ve L (+) Laktik Asit ile Bazı Biyokimyasal ve Hematolojik Parametrelerin Diagnostik ve Prognostik Açıdan Öneminin Belirlenmesi. Kafkas Üniv Vet Fak Derg. 19 (Suppl-A): 167-173.

24. Yılmaz Ş. (2008). Koroner Arter Baypas Cerrahisinde Hiperlaktemi: Belirleyicileri ve Mortalite İlişkisi. Uzmanlık tezi. Göğüs Kalp ve Damar Cerrahisi, Eğitim ve Araştırma Hastanesi Anesteziyoloji ve Reanimasyon Kliniği, İstanbul.

25. Backer D, Creteur J, Zhang H, Norrenberg M, Vincent JL. (1997) Lactate Production by the Lungs in Acute Lung Injury. Am J Respir Crit Care Med. 156(4):1099-1104.

26. Coghe J, Uystepruyst $\mathrm{CH}$, Bureau F, Detılleux J, Art T, Lekeux P. (2000). Validation and Prognostic Value of Plasma Lactate Measurement in Bovine Respiratory Disease. Vet J. 160(2): 139146.

27. Ok M, Güzelbekteş H, Şen I, Coşkun A. (2005). Kuzularda Deneysel Oluşturulan Solunum Sistemi Enfeksiyonlarının Teşhisinde Arteriyel Kan Gazının Önemi. Vet Bil Derg. 21(3-4): 119-125.

Sorumlu Yazar:
Cumali ÖZKAN
Van Yüzüncü Yıl Üniversitesi, Veteriner Fakültesi, İç Has-
talıkları Anabilim Dalı, 65080 Van, TÜRKiYE
E-posta: cumaliozkan@gmail.com

